\title{
DESAIN PELAT GEDUNG STRUKTUR BETON BERTULANG DI WILAYAH GEMPA TINGGI
}

\author{
Alfian Wiranata Zebua \\ Program Studi Pendidikan Teknik Bangunan FPTK \\ IKIP Gunungsitoli \\ E-mail : alfianzeb@yahoo.com
}

\begin{abstract}
Abstrak
Peristiwa gempa yang selalu terjadi di berbagai wilayah di Indonesia menyebabkan perencanaan ketahanan gedung terhadap gempa harus diperhatikan. Penelitian ini bertujuan untuk mendesain pelat lantai dan pelat atap beton bertulang di wilayah gempa tinggi. Model struktur yang dianalisis adalah gedung lantai 4 di Kota Gunungsitoli. Pelat direncanakan sebagai pelat satu arah. Pembebanan disesuaikan dengan SNI 1727:2013, sedangkan perencanaan struktur beton disesuaikan dengan SNI 2847:2013. Dari hasil perencanaan diperoleh tebal plat lantai atap $10 \mathrm{~cm}$ dengan tulangan pokok $\varnothing 10-200$ dan tulangan susut $\varnothing 8-200$. Tebal pelat lantai $12 \mathrm{~cm}$ dengan tulangan pokok Ø10-200 dan tulangan susut Ø8-150.
\end{abstract}

Kata Kunci : Pelat Beton Bertulang, Wilayah Gempa Tinggi

\begin{abstract}
The effect of earthquake loads have to be considered when we need to design a building in Indonesia because of the earthquake happen almost on every region in Indonesia. This study mean to achieve slab design. Four stories building in Gunungsitoli city used as structure model. Slab has been design as one way slab. Loads considered in SNI 1727:2013, while the design process according to SNI 2847:2013. From this study, the dimension of roof slab is $10 \mathrm{~cm}$, while reinforced are $\emptyset 10-200$ and $\varnothing 8-200$. The dimension of floor slab is $12 \mathrm{~cm}$, while reinforced are $\emptyset 10-200$ and $\emptyset 8-150$.
\end{abstract}

Keywords : Slab, High Risk Earthquake Region

\section{A. PENDAHULUAN}

Kebutuhan akan tempat tinggal adalah keniscayaan bagi manusia. Dari waktu ke waktu manusia berusaha untuk menaikkan taraf hidup mereka dengan adanya perkembangan dan kemajuan teknologi yang sampai sekarang ini semakin canggih. Dengan adanya peningkatan taraf hidup ini, kebutuhan dan permintaan manusia pun semakin banyak dan kompleks. Manusia perlu bekerja keras mencari nafkah dengan cara apa saja untuk dapat memenuhi seluruh kebutuhannya.

Perkembangan taraf kehidupan masyarakat Nias pasca gempa 2005 yang semakin meningkat menimbulkan kebutuhan akan bangunan gedung yang lebih besar daripada sebelumnya. Kebutuhan bangunan gedung dari gedung tidak bertingkat sampai ke bangunan bertingkat semakin bertambah. Bangunan pemerintahan 
maupun swasta dibutuhkan lebih besar kapasitasnya untuk mengakomodasi perkembangan kehidupan masyarakat. Seiring dengan hal tersebut, bangunan rumah tinggal bertingkat juga dibutuhkan masyarakat dengan taraf ekonomi kelas menengah ke atas.

Dalam merealisasikan suatu konstruksi sebuah bangunan khususnya bangunan dengan tingkat tiga ke atas diperlukan sebuah perencanaan yang matang agar terbentuknya sebuah bangunan yang memiliki kualitas dan mutu yang baik. Perencanaan dapat diartikan sebagai suatu bentuk usaha dalam menyusun, mengatur atau mengorganisasikan kegiatan-kegiatan yang terdapat dalam sebuah proyek pembangunan sehingga menghasilkan output (hasil) yang sesuai dengan keinginan bersama (pemilik, perencana dan pelaksana proyek) dengan tetap memperhatikan standar ekonomis, keamanan, kekuatan dan kenyamanan.

Berdasarkan fakta bahwa potensi gempa di Kota Gunungsitoli Kepulauan Nias sangat besar, maka sangat perlu diketahui desain pelat gedung beton bertulang di wilayah gempa tinggi sesuai dengan peraturan-peraturan terbaru yang dikeluarkan oleh pemerintah.

\section{B. TINJAUAN PUSTAKA}

\section{Filosofi Desain}

Pendekatan probabilitas untuk sifat-sifat struktur dan kondisi pembebanan menuju ke suatu filosofi batasan desain, yang dapat diterima secara umum. Tujuan pendekatan ini yaitu untuk memastikan bahwa seluruh komponen struktur direncanakan untuk mampu menahan kelebihan beban (faktor keamanan) dan perubahan bentuk yang dapat terjadi selama masa pembangunan konstruksi maupun dalam masa penggunaan bangunan tersebut.
Ruang lingkup perencanaan sebuah bangunan gedung meliputi beberapa tahapan-tahapan yaitu mulai dari tahap persiapan, studi kelayakan, mendesain bangunan, perhitungan struktur dan perhitungan biaya. Perencanaan sebuah konstruksi bangunan merupakan sebuah sistem yang sebaiknya dilakukan dengan tahapan-tahapan tertentu agar konstruksi yang dihasilkan sesuai dengan tujuan bersama yang ingin dicapai.

\section{Struktur Beton Bertulang}

Beton bertulang adalah beton yang ditulangi dengan luas dan jumlah tulangan yang tidak kurang dari nilai minimum yang dipersyaratkan dan direncanakan bahwa kedua bahan tersebut bekerja sama dalam memikul gaya-gaya yang terjadi di dalam bangunan. Beton bertulang terbuat dari gabungan antara beton dan tulangan baja. Oleh karena itu, beton bertulang memiliki sifat yang sama dengan bahanbahan penyusunnya yaitu sangat kuat terhadap beban tekan dan beban tarik.

Sistem struktur bangunan yang dibuat dengan beton bertulang dirancang dari prinsip dasar desain dan penelitian elemen beton bertulang yang menerima gaya-gaya dalam seperti gaya geser, gaya aksial, momen lentur dan momen puntir. Di dalam struktur ini, memiliki kekuatan tekan yang besar namum lemah terhadap tegangan tarik. Karena itulah baja tulangan ditanam di dalam beton untuk menahan tegangan tarik yang terjadi.

\section{Pelat Lantai}

Pelat lantai merupakan suatu struktur solid tiga dimensi dengan bidang permukaan yang lurus, datar dan tebalnya jauh lebih kecil dibandingkan dengan dimensinya yang lain. Struktur pelat bisa saja dimodelkan dengan 
elemen 3 dimensi yang mempunyai tebal h, panjang b, dan lebar a. Adapun fungsi dari pelat lantai adalah untuk menerima beban yang akan disalurkan ke struktur lainnya.

Pada pelat lantai merupakan beton bertulang yang diberi tulangan baja dengan posisi melintang dan memanjang yang diikat menggunakan kawat bendrat, serta tidak menempel pada permukaan pelat baik bagian bawah maupun atas. Adapun ukuran diameter, jarak antar tulangan, posisi tulangan tambahan bergantung pada bentuk pelat, kemampuan yang diinginkan untuk pelat menerima lendutan yang diijinkan.

Untuk merencanakan pelat beton bertulang yang perlu dipertimbangkan tidak hanya pembebanan saja, tetapi juga jenis perletakan dan jenis penghubung di tempat tumpuan. Kekakuan hubungan antara pelat dan tumpuan akan menentukan besar momen lentur yang terjadi pada pelat.

\section{Pelat Satu Arah}

Pelat dengan tulangan pokok satu arah ini akan dijumpai jika pelat beton lebih dominan menahan beban yang berupa momen lentur pada bentang satu arah saja.Contoh pelat satu arah adalah pelat kantilever (luifel) dan pelat yang ditumpu oleh 2 tumpuan.

Karena momen lentur hanya bekerja pada 1 arah saja, yaitu searah bentang L (lihat gambar di bawah), maka tulangan pokok juga dipasang 1 arah yang searah bentang $\mathrm{L}$ tersebut. Untuk menjaga agar kedudukan tulangan pokok (pada saat pengecoran beton) tidak berubah dari tempat semula maka dipasang pula tulangan tambahan yang arahnya tegak lurus tulangan pokok. Tulangan tambahan ini lazim disebut : tulangan bagi.

Kedudukan tulangan pokok dan tulangan bagi selalu bersilangan tegak lurus, tulangan pokok dipasang dekat dengan tepi luar beton, sedangkan tulangan bagi dipasang di bagian dalamnya dan menempel pada tulangan pokok. Tepat pada lokasi persilangan tersebut, kedua tulangan diikat kuat dengan kawat pengikat. Fungsi tulangan bagi, selain memperkuat kedudukan tulangan pokok, juga sebagai tulangan untuk penahan retak beton akibat susut dan perbedaan suhu beton. Pembebanan yamg terjadi didasarkan pada SNI 1727:2013. Perencanaan pelat satu arah disesuaikan dengan SNI 2847:2013.

\section{Pembebanan}

Menurut SNI 1727:2013 tentang beban minimum untuk perancangan bangunan gedung dan struktur lain, beban-beban yang bekerja pada suatu konstruksi bangunan adalah :

a. Beban mati adalah berat seluruh bahan konstruksi bangunan gedung yang terpasang, termasuk dinding, lantai, atap, plafon, tangga, dinding partisi, finishing, klading gedung dan komponen arsitektural dan struktural lainnya serta peralatan layan terpasang lain termasuk berat keran.

b. Beban hidup ialah beban yang diakibatkan oleh pengguna dan penghuni bangunan gedung atau struktur lain yang tidak termasuk beban konstruksi, dan ke dalamnya termasuk beban-beban pada lantai yang berasal dari barang-barang yang dapat berpindah, mesin-mesin serta peralatan yang tidak merupakan bagian yang tak terpisahkan dari gedung dan dapat diganti selama masa hidup dari gedung itu, sehingga mengakibatkan perubahan dalam pembebanan lantai tersebut. Beban hidup atap ialah beban pada atap yang diakibatkan (1) pelaksanaan pemeliharaan oleh pekerja, 
peralatan dan material dan (2) selama masa layan struktur yang diakibatkan oleh benda bergerak seperti tanaman atau benda dekorasi kecil yang tidak berhubungan dengan penghunian.

c. Beban angin ialah semua beban yang bekerja pada gedung atau bagian gedung yang diakibatkan oleh selisih dalam tekanan udara.

d. Beban gempa ialah semua beban statik ekuivalen yang bekerja pada gedung atau bagian gedung yang menirukan pengaruh dari gerakan tanah akibat gempa itu.

e. Beban khusus ialah semua beban hidup yang bekerja pada gedung atau bagian gedung yang terjadi akibat selisih suhu, pengangkatan dan pemasangan, penurunan fondasi, susut, gaya-gaya tambahan yang berasal dari beban hidup seperti gaya rem yang berasal dari keran, gaya sentrifugal dan gaya dinamis yang berasal dari mesinmesin, serta pengaruh-pengaruh khusus lainnya.

\section{METODE PENELITIAN}

Dalam perencanaan struktur pelat beton bertulang pada dasarnya menumpu pada balok beton bertulang, agar perencanaan lebih mengutamakan keselamatan, cara mengetahui ukuran lebar balok dan tinggi balok sebagai tumpuan pelat, sesuai SNI 03-28472013.

Dilihat dari denah pada gedung ini direncanakan satu tipe pelat yaitu pelat satu arah. Dalam perencanaan tulangan pelat, tumpuan pada pelat dianggap jepit penuh. Metode yang digunakan dalam analisis pelat beton bertulang di Indonesia adalah sebagai berikut :

a. Beban tersendiri dari beban hidup dan beban mati

b. Asumsi perletakan adalah tertumpu bebas pada tumpuan tepi

c. Analisis struktur sesuai hasil penelitian Zebua, A.W (2016)

d. Analisis beton bertulang sesuai SNI 03-2847-2013

Pada penelitian ini akan ditinjau satu model struktur gedung yaitu struktur gedung beraturan berlantai 4 . Adapun data-data teknis yang digunakan dalam analisis adalah sebagai berikut:
a. Lokasi bangunan
: Kota Gunungsitoli
b. Jenis bangunan : Rumah Tinggal
c. Konstruksi bangunan : Struktur beton bertulang
d. Sistem struktur

: Sistem rangka pemikul momen khusus (SRPMK)

e. Dimensi struktur :
1). Plat lantai $=12 \mathrm{~cm}$
2). Plat atap $=10 \mathrm{~cm}$
3). Balok $=30 \times 50 \mathrm{~cm}$
4). Kolom lantai $1 \& 2$ $=55 \times 55 \mathrm{~cm}$
5). Kolom lantai $3 \& 4$ $=45 \mathrm{x} 45 \mathrm{~cm}$

f. Gambar Struktur, dapat dilihat pada gambar 1 sampai 4. 


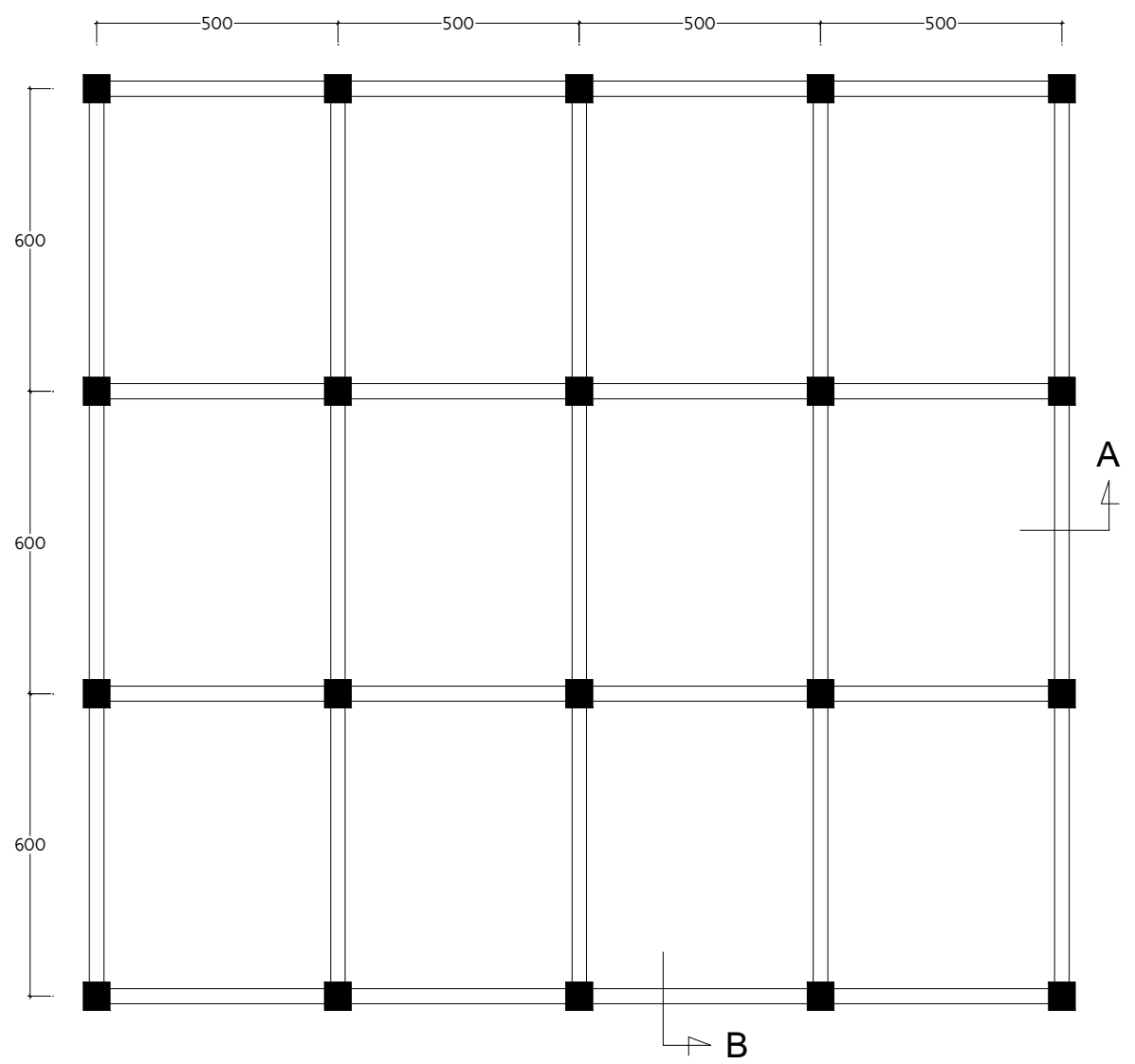

Gambar 1. Denah Model Struktur

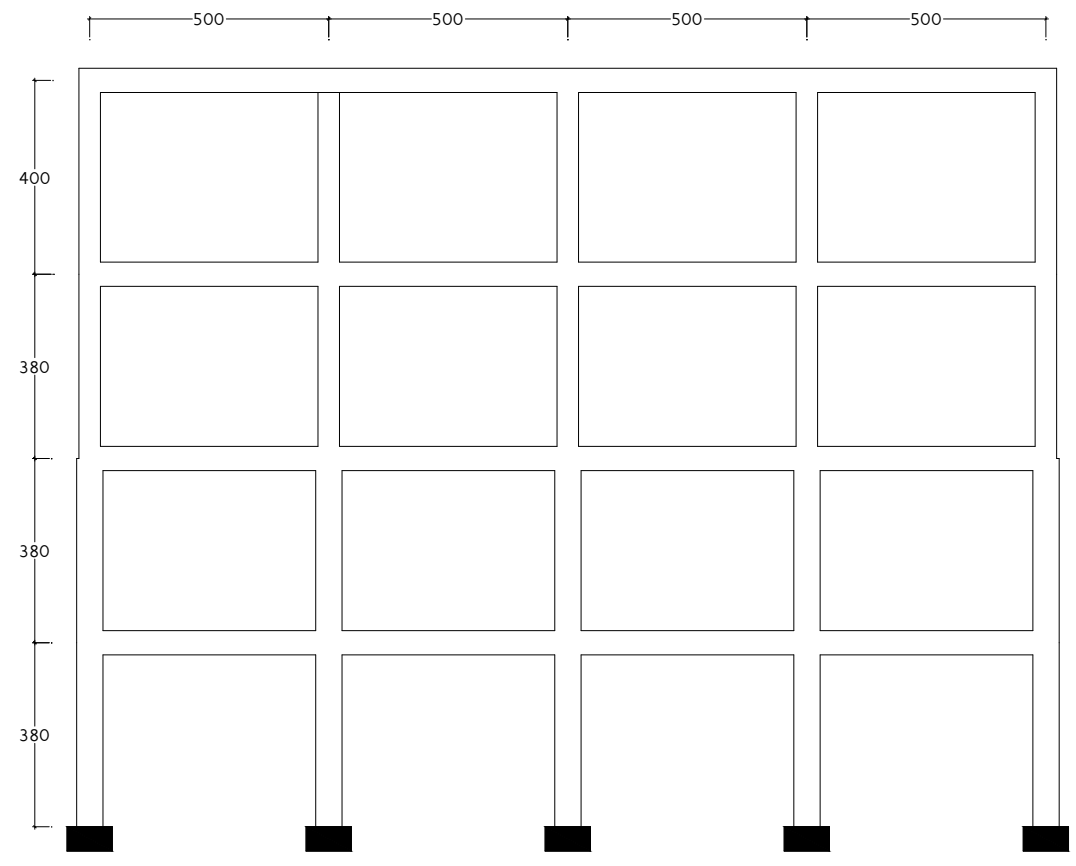

Gambar 2. Potongan A-A 


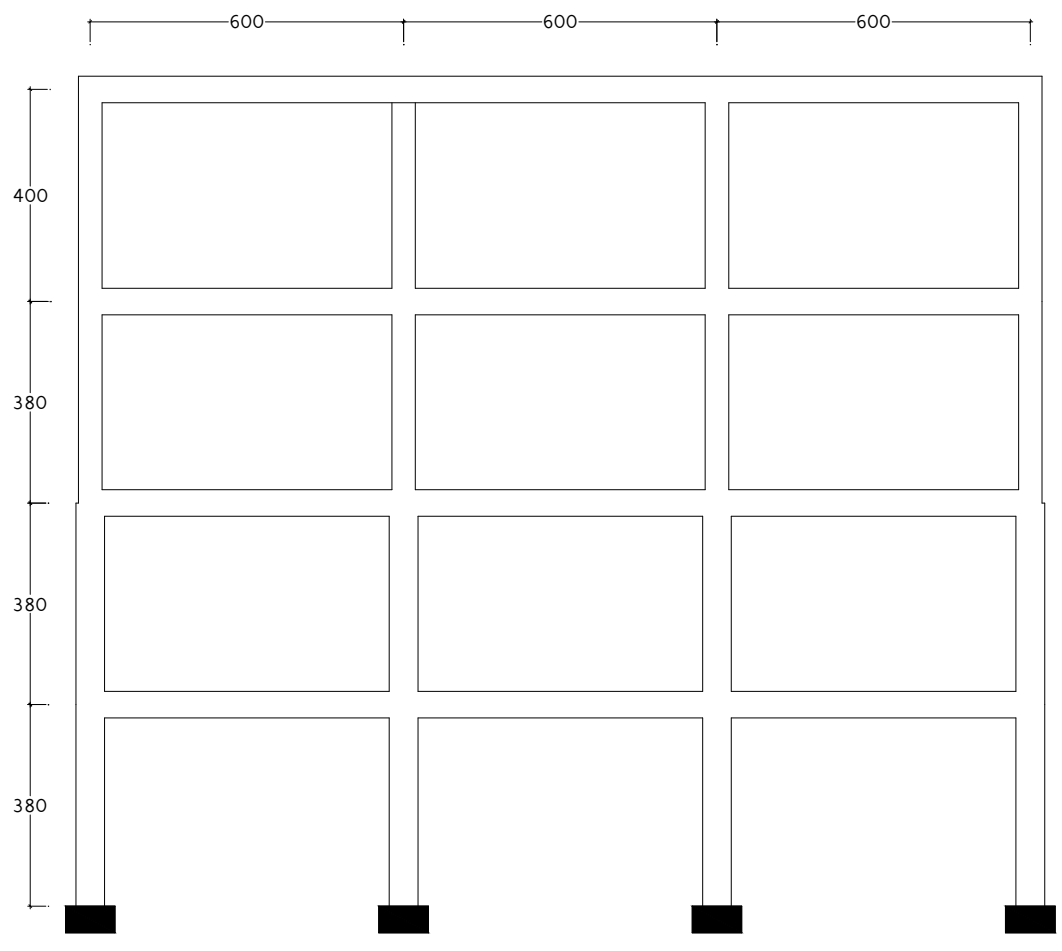

Gambar 3. Potongan B-B

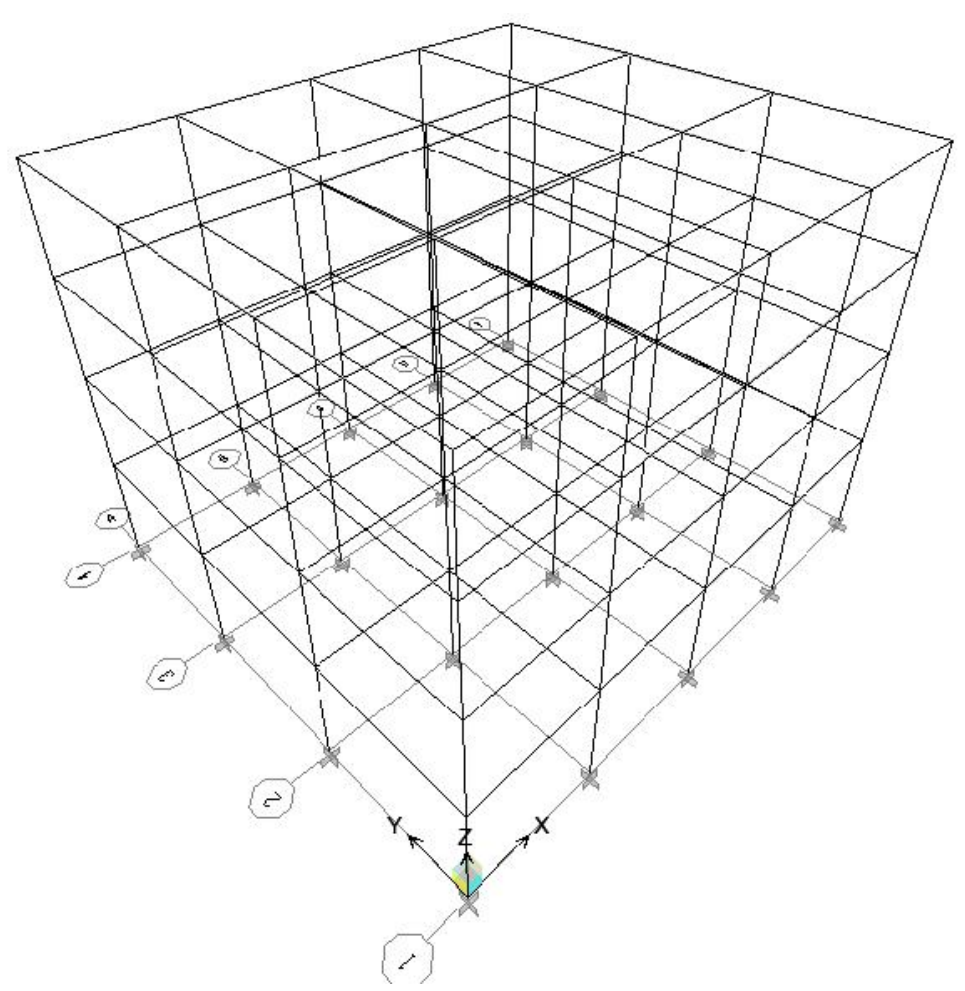

Gambar 4. Perspektif Model Stuktur 
D. HASIL DAN PEMBAHASAN

1. Hasil Perhitungan Tebal Slab Lantai

Direncanakan :

$$
\begin{aligned}
& \mathrm{fc}^{\prime}=25 \mathrm{MPa} \\
& \mathrm{fy}=240 \mathrm{MPa}(\text { diameter } \leq 12 \mathrm{~mm}) \\
& \text { fy }=420 \mathrm{MPa}(\text { diamater }>12 \mathrm{~mm})
\end{aligned}
$$

Menentukan tebal slab 2,5 x $6 \mathrm{~m}^{2}$ :

$$
\frac{l y}{l x}=\frac{6000}{2500}=2,4<2 \text {, }
$$

dianggap sebagai struktur pelat satu arah.

Bentang plat $(\mathrm{L})=2500 \mathrm{~mm}$

Sesuai SNI 2847:2013, untuk kedua ujung menerus pada pelat masif satu arah adalah :

$$
\begin{aligned}
h_{\text {min }} & =\frac{1}{28} L\left(0,4+\frac{f y}{700}\right) \\
h_{\text {min }} & =\frac{1}{28} \cdot 2500 \cdot\left(0,4+\frac{240}{700}\right) \\
\mathrm{h}_{\min } & =66,326 \mathrm{~mm}
\end{aligned}
$$

Dengan demikian dipakai tebal pelat $120 \mathrm{~mm}$ untuk pelat lantai dan tebal 100 $\mathrm{mm}$ untuk pelat atap dapat digunakan.

\section{Hasil Perhitungan Pembebanan Pelat}

a. Beban Rencana Pelat lantai

\section{Beban Mati}

Berat sendiri pelat lantai

$=0,12 \times 24$

$=2,88 \mathrm{kN} / \mathrm{m}^{2}$
Berat spesi keramik (20 mm)

$=0,02 \times 42$

$=0,84 \mathrm{kN} / \mathrm{m}^{2}$

Berat keramik $(30 \mathrm{~mm})$

$=0,03 \times 24$

$=0,72 \mathrm{kN} / \mathrm{m}^{2}$

Berat plafon dan penggantung

$=0,18 \mathrm{kN} / \mathrm{m}^{2}$

Total beban mati $\mathrm{QDL}=4,62 \mathrm{kN} / \mathrm{m}^{2}$

Beban Hidup (SNI 1727:2013), $\mathrm{Q}_{\mathrm{LL}}=1,92 \mathrm{kN} / \mathrm{m}^{2}$

Beban Terfaktor

$\mathrm{Wu}=1,2 \mathrm{Q}_{\mathrm{DL}}+1,6 \mathrm{Q}_{\mathrm{LL}}$

$=1,2 \times 4,62+1,6 \times 1,92$

$\mathrm{Wu}=8,62 \mathrm{kN} / \mathrm{m}^{2}$

b. Beban Rencana Pelat Atap

Beban Mati

Berat sendiri pelat lantai

$=0,10 \times 24$

$=2,4 \mathrm{kN} / \mathrm{m}^{2}$

Berat spesi $(20 \mathrm{~mm})$

$=0,02 \times 42$

$=0,84 \mathrm{kN} / \mathrm{m}^{2}$

Berat plafon dan penggantung

$=0,18 \mathrm{kN} / \mathrm{m}^{2}$

Total beban mati QDL $=3,42 \mathrm{~N} / \mathrm{m}^{2}$

Beban Hidup (SNI 1727:2013), $\mathrm{Q}_{\mathrm{LL}}=0,96 \mathrm{kN} / \mathrm{m}^{2}$

Beban Terfaktor

$\mathrm{Wu}=1,2 \mathrm{Q}_{\mathrm{DL}}+1,6 \mathrm{Q}_{\mathrm{LL}}$

$=1,2 \times 3,42+1,6 \times 0,96$

$\mathrm{Wu}=5,64 \mathrm{kN} / \mathrm{m}^{2}$ 


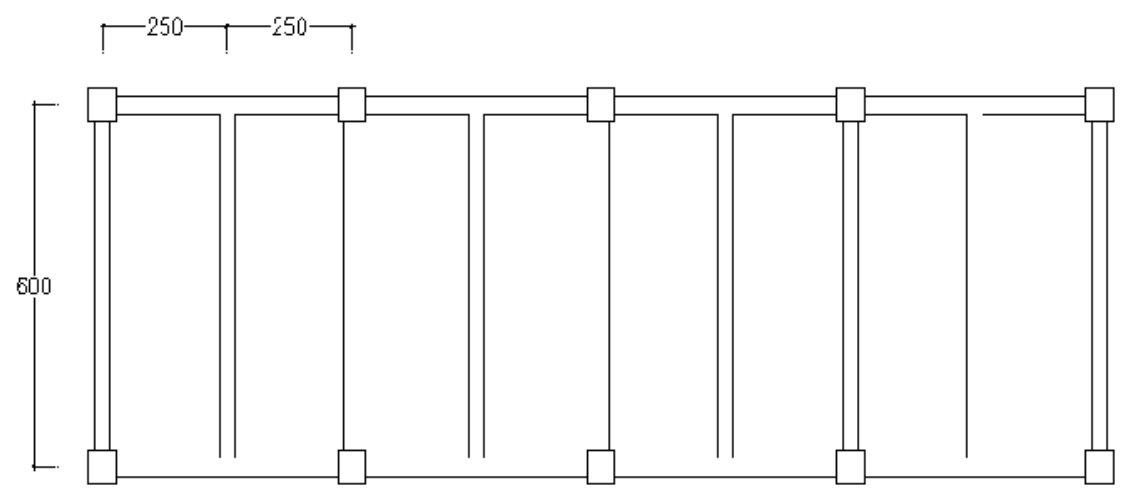

Gambar 5. Denah Pelat Lantai

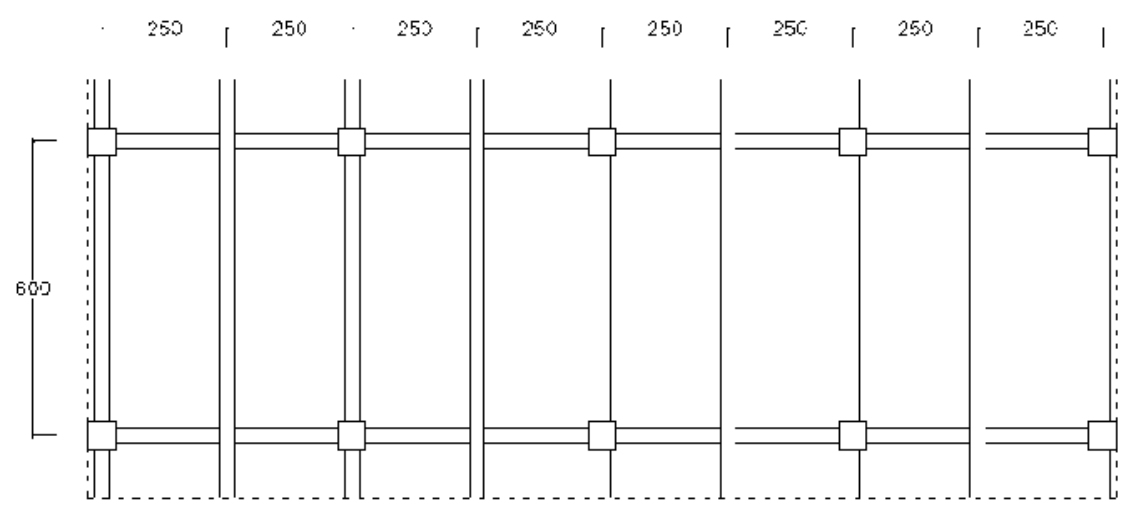

Gambar 6. Sketsa Ujung Menerus

\section{Hasil Perhitungan Momen Pelat}

Berdasarkan pasal 8.3.3 SNI 2847:2013, koefisien momen pelat satu arah menerus (tiga bentang atau lebih) dapat dilihat pada gambar 7 .

Untuk menghitung momen terfakor digunakan rumus :

$$
\mathrm{M}_{\mathrm{u}} \quad=\mathrm{C}_{\mathrm{m}} \cdot\left(\mathrm{W}_{\mathrm{u}} \cdot \mathrm{L}\right)
$$

Dengan :

$\mathrm{C}_{\mathrm{m}}=$ Koefisien Momen

a. Momen Pelat Lantai

$\mathrm{Mu}$ Tumpuan (titik A dan B)

$=\frac{1}{24} \cdot \mathrm{W}_{\mathrm{u}} \cdot . \mathrm{L}^{2}$

$=\frac{1}{24} \cdot(8,62) \cdot(2,5)^{2}$

$=2,25 \mathrm{kNm}$
Mu Tumpuan (titik C)

$=\frac{1}{9} \cdot \mathrm{W}_{\mathrm{u}} \cdot . \mathrm{L}^{2}$

$=\frac{1}{9} \cdot(8,62) \cdot(2,5)^{2}$

$=5,98 \mathrm{kNm}$

Mu Lapangan

$=\frac{1}{14} \cdot \mathrm{W}_{\mathrm{u}} \cdot . \mathrm{L}^{2}$

$=\frac{1}{14} \cdot(8,62) \cdot(2,5)^{2}$

$=3,85 \mathrm{kNm}$

Momen yang dipakai adalah momen terbesar, sehingga $\mathrm{Mu}=$ $5,98 \mathrm{kNm}$ 


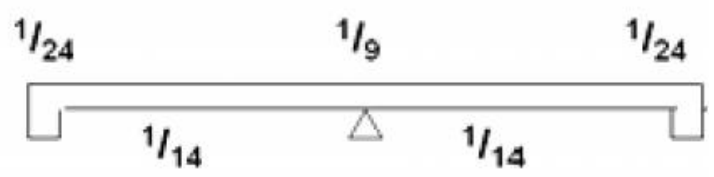

Gambar 7. Momen Pelat

b. Momen Pelat Atap

Mu Tumpuan (titik A dan B)

$$
\begin{aligned}
& =\frac{1}{24} \cdot \mathrm{W}_{\mathrm{u}} \cdot \mathrm{L}^{2} \\
& =\frac{1}{24} \cdot(5,64) \cdot(2,5)^{2} \\
& =1,47 \mathrm{kNm}
\end{aligned}
$$

$\mathrm{Mu}$ Tumpuan (titik C)

$$
\begin{aligned}
& =\frac{1}{9} \cdot \mathrm{W}_{\mathrm{u}} \cdot . \mathrm{L}^{2} \\
& =\frac{1}{9} \cdot(5,64) \cdot(2,5)^{2} \\
& =5,98 \mathrm{kNm}
\end{aligned}
$$

Mu Lapangan

$$
\begin{aligned}
& =\frac{1}{14} \cdot \mathrm{W}_{\mathrm{u}} \cdot . \mathrm{L}^{2} \\
& =\frac{1}{14} \cdot(5,64) \cdot(2,5)^{2} \\
& =2,52 \mathrm{kNm}
\end{aligned}
$$

Momen yang dipakai adalah momen terbesar, sehingga $\mathrm{Mu}=$ $3,91 \mathrm{kNm}$.

\section{Hasil Perhitungan Tulangan Pelat Lantai}

Digunakan:

Tulangan pokok diameter 10

$=78,54 \mathrm{~mm}^{2}$

Tulangan susut diameter 8

$=50,27 \mathrm{~mm}^{2}$

Selimut beton pelat

$=20 \mathrm{~mm}$
Tinggi efektif (d)

$=$ tebal plat - (selimut beton $+0,5$. diameter tulangan pokok)

$=120-(20+0,5.10)$

$=95 \mathrm{~mm}$

a. Tulangan Pokok

$\mathrm{Mu}=5,98 \mathrm{kNm}$

$$
\begin{aligned}
\mathrm{R}_{\mathrm{n}} & =\frac{\mathrm{M}_{\mathrm{u}}}{0,9 \cdot \mathrm{b} \cdot \mathrm{d}^{2}} \\
& =\frac{5,98 \cdot 10^{6}}{0,9 \cdot 1000 \cdot 95^{2}} \\
& =0,74 \\
\rho_{\text {perlu }} & =\frac{0,85 \mathrm{f}_{\mathrm{c}}{ }^{\prime}}{\mathrm{f}_{\mathrm{y}}}\left(1-\sqrt{1-\frac{2 \mathrm{R}_{\mathrm{n}}}{0,85 \mathrm{f}_{\mathrm{c}}{ }^{\prime}}}\right) \\
& =\frac{0,85 \cdot 25}{240}\left(1-\sqrt{1-\frac{2 \cdot 0,74}{0,85 \cdot 25}}\right) \\
& =0,0031
\end{aligned}
$$

$\rho_{\max }=0,0025$ (SNI 2847:2013)

$\rho_{\text {min }}<\rho_{\text {perlu }}<\rho_{\max }$, maka digunakan $\rho_{\text {perlu }}=0,0031$

$\mathrm{A}_{\text {s perlu }}=0,0031 \times 1000 \times 95$

$$
=296,65 \mathrm{~mm}^{2}
$$

Berdasarkan pasal 7.12.2.1 SNI 2847:2013, luasan tulangan susut dan suhu menyediakan paling sedikit memiliki rasio tulangan terhadap luas bruto penampang beton sebagai berikut :

1). Slab dengan batang tulangan mutu fy $=280 \mathrm{MPa}$ atau fy $=$ $350 \mathrm{MPa}$ adalah 0,002 
2). Slab dengan batang tulangan mutu fy $=420 \mathrm{MPa}$ adalah 0,0018

Untuk slab dengan batang tulangan mutu $240 \mathrm{MPa}, \rho=0,002$

$$
\begin{aligned}
\mathrm{A}_{\mathrm{s} \text { min }} & =0,002 \times 1000 \times 120 \\
& =240 \mathrm{~mm}^{2}
\end{aligned}
$$

Karena As min < As perlu, maka digunakan As perlu $=296,65 \mathrm{~mm}^{2}$, digunakan tulangan $\mathrm{P} 10 \quad\left(\mathrm{Av}_{\mathrm{v}}=\right.$ $78,54 \mathrm{~mm}^{2}$ )

$$
\begin{aligned}
\text { Spasi } & =\frac{1000 . A_{\mathrm{v}}}{\mathrm{A}_{\mathrm{S}}} \\
& =\frac{1000.78,54}{296,65} \\
& =264,75 \mathrm{~mm}
\end{aligned}
$$

Sesuai pasal 13.3.2 SNI 2847:2013, spasi tulangan pada penampang kritis tidak boleh melebihi dua kali tebal slab maka digunakan spasi $200 \mathrm{~mm}$.

$$
\begin{aligned}
\mathrm{A}_{\mathrm{s}} & =\frac{1000 . \mathrm{A}_{\mathrm{v}}}{\text { spasi }} \\
& =\frac{1000.78,54}{200} \\
& =393 \mathrm{~mm}^{2}
\end{aligned}
$$

$$
\begin{array}{lll}
\mathrm{A}_{\mathrm{s}} & >\mathrm{A}_{\text {sperlu }} \\
393 \mathrm{~mm}^{2} & >296,65 \mathrm{~mm}^{2} \quad(\mathrm{OK})
\end{array}
$$

Digunakan tulangan diameter $10-200\left(\right.$ As $\left.=393 \mathrm{~mm}^{2}\right)$.

b. Tulangan Susut dan Suhu

$$
\begin{aligned}
A_{\text {s perlu }} & =0,002 \times 1000 \times 120 \\
& =240 \mathrm{~mm}^{2}
\end{aligned}
$$

Digunakan tulangan P8 $\left(\mathrm{A}_{\mathrm{s}}=50,27\right)$

$$
\begin{aligned}
\text { Spasi } & =\frac{1000 \cdot A_{v}}{A_{s}} \\
& =\frac{1000.50,27}{240} \\
& =209,46 \mathrm{~mm}
\end{aligned}
$$

Dicoba spasi $150 \mathrm{~mm}$

$$
\begin{array}{rlrl} 
& \mathrm{A}_{\mathrm{s}} & = & \frac{1000 \cdot \mathrm{A}_{\mathrm{v}}}{\text { spasi }} \\
& =\frac{1000 \cdot 50,27}{150} \\
& =335,13 \mathrm{~mm}^{2} \\
& >\mathrm{A}_{\text {sperlu }} \\
\mathrm{A}_{\mathrm{s}} & >296,65 \mathrm{~mm}^{2} \quad(\mathrm{OK}) \\
335,13 \mathrm{~mm}^{2}
\end{array}
$$

Digunakan tulangan diameter 8-150 $\mathrm{mm}\left(\mathrm{As}=335,13 \mathrm{~mm}^{2}\right)$.

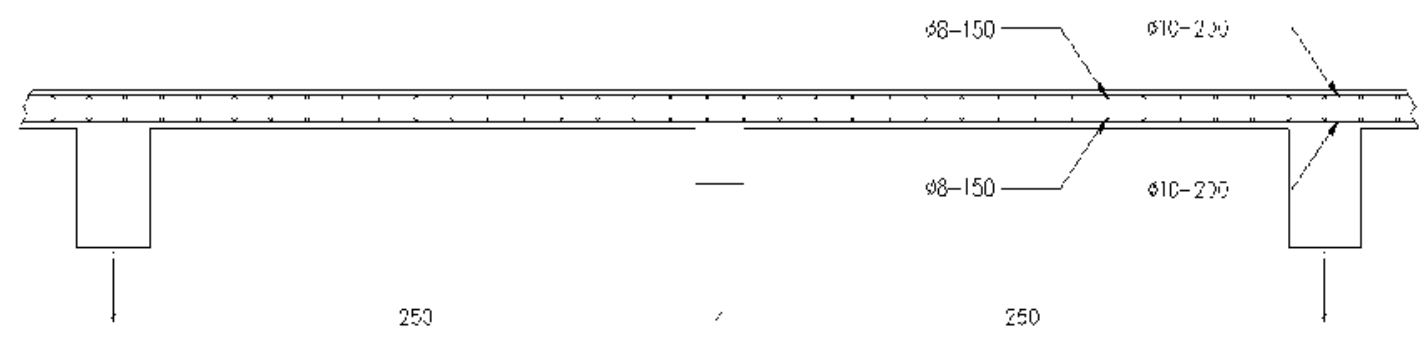

Gambar 8. Penulangan Pelat Lantai 


\section{Hasil Perhitungan Tulangan Atap}

Digunakan:

Tulangan pokok diameter 10

$=78,54 \mathrm{~mm}^{2}$

Tulangan susut diameter 8

$=50,27 \mathrm{~mm}^{2}$

Selimut beton pelat

$=20 \mathrm{~mm}$

Tinggi efektif (d)

$=$ tebal plat - (selimut beton $+0,5$. diameter tulangan pokok)

$=100-(20+0,5.10)$

$=75 \mathrm{~mm}$

a. Tulangan Pokok

$\mathrm{Mu}=3,91 \mathrm{kNm}$

$$
\begin{aligned}
\mathrm{R}_{\mathrm{n}} & =\frac{\mathrm{M}_{\mathrm{u}}}{0,9 \cdot \mathrm{b} \cdot \mathrm{d}^{2}} \\
& =\frac{3,91 \cdot 10^{6}}{0,9 \cdot 1000 \cdot 75^{2}} \\
& =0,77 \\
\rho_{\text {perlu }} & =\frac{0,85 \mathrm{f}_{\mathrm{c}}{ }^{\prime}}{\mathrm{f}_{\mathrm{y}}}\left(1-\sqrt{1-\frac{2 \mathrm{R}_{\mathrm{n}}}{0,85 \mathrm{f}_{\mathrm{c}}{ }^{\prime}}}\right) \\
& =\frac{0,85 \cdot 25}{240}\left(1-\sqrt{1-\frac{2 \cdot 0,77}{0,85 \cdot 25}}\right) \\
& =0,0033
\end{aligned}
$$

$\rho_{\max }=0,0025($ SNI 2847:2013)

$\rho_{\text {min }}<\rho_{\text {perlu }}<\rho_{\text {max }}$, maka digunakan $\rho_{\text {perlu }}=0,0033$

$$
\begin{aligned}
\mathrm{A}_{\text {s perlu }} & =0,0033 \times 1000 \times 75 \\
& =245,91 \mathrm{~mm}^{2}
\end{aligned}
$$

Berdasarkan pasal 7.12.2.1 SNI 2847:2013, luasan tulangan susut dan suhu menyediakan paling sedikit memiliki rasio tulangan terhadap luas bruto penampang beton sebagai berikut :
1). Slab dengan batang tulangan mutu fy $=280 \mathrm{MPa}$ atau fy $=$ $350 \mathrm{MPa}$ adalah 0,002

2). Slab dengan batang tulangan mutu fy $=420 \mathrm{MPa}$ adalah 0,0018

Untuk slab dengan batang tulangan mutu $240 \mathrm{MPa}, \rho=0,002$

$$
\begin{aligned}
\mathrm{A}_{\mathrm{s} \text { min }} & =0,002 \times 1000 \times 100 \\
& =200 \mathrm{~mm}^{2}
\end{aligned}
$$

Karena As min < As perlu , maka digunakan As perlu $=245,91 \mathrm{~mm}^{2}$, digunakan tulangan $\mathrm{P} 10 \quad\left(\mathrm{~A}_{\mathrm{v}}=\right.$ $78,54 \mathrm{~mm}^{2}$ )

$$
\begin{aligned}
\text { Spasi } & =\frac{1000 \cdot \mathrm{A}_{\mathrm{v}}}{\mathrm{A}_{\mathrm{s}}} \\
& =\frac{1000.78,54}{245,91} \\
& =319,38 \mathrm{~mm}
\end{aligned}
$$

Sesuai pasal 13.3.2 SNI 2847:2013, spasi tulangan pada penampang kritis tidak boleh melebihi dua kali tebal slab maka digunakan spasi $200 \mathrm{~mm}$.

$$
\begin{array}{rl}
\mathrm{A}_{\mathrm{s}} & =\frac{1000 \cdot \mathrm{A}_{\mathrm{v}}}{\text { spasi }} \\
& =\frac{1000 \cdot 78,54}{200} \\
& =393 \mathrm{~mm}^{2} \\
& >\mathrm{A}_{\mathrm{sperlu}} \\
\mathrm{A}_{\mathrm{s}} & \\
393 \mathrm{~mm}^{2} & 245,91 \mathrm{~mm}^{2} \quad(\mathrm{OK}) \\
\begin{array}{l}
\text { Digunakan } \\
10-200(\text { tulangan }
\end{array} & \left.393 \mathrm{~mm}^{2}\right) .
\end{array}
$$

b. Tulangan Susut dan Suhu

$$
\begin{aligned}
\mathrm{A}_{\text {s perlu }} & =0,002 \times 1000 \times 100 \\
& =200 \mathrm{~mm}^{2}
\end{aligned}
$$

Digunakan tulangan P8 $\left(\mathrm{As}_{\mathrm{s}}=50,27\right)$ 


$$
\begin{aligned}
\text { Spasi } & =\frac{1000 . A_{v}}{A_{s}} \\
& =\frac{1000.50,27}{200} \\
& =251,33 \mathrm{~mm}
\end{aligned}
$$

Dicoba spasi $200 \mathrm{~mm}$

$$
\mathrm{A}_{\mathrm{s}} \quad=\frac{1000 . \mathrm{A}_{\mathrm{v}}}{\text { spasi }}
$$

$$
\begin{aligned}
& =\frac{1000.50,27}{200} \\
& =251,33 \mathrm{~mm}^{2}
\end{aligned}
$$

$\mathrm{A}_{\mathrm{s}} \quad>\mathrm{A}_{\text {sperlu }}$

$251,33 \mathrm{~mm}^{2}>245,91 \mathrm{~mm}^{2} \quad(\mathrm{OK})$

Digunakan tulangan diameter 8-200 $\mathrm{mm}\left(\mathrm{As}=335,13 \mathrm{~mm}^{2}\right)$

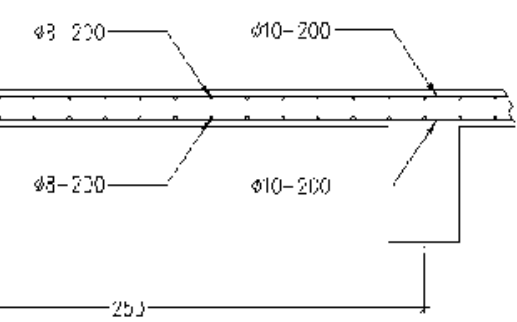

Gambar 9. Penulangan Pelat Atap

\section{E. KESIMPULAN}

Berdasarkan hasil perhitungan di atas, maka dapat diambil kesimpulan pada model struktur yang dianalisis, diperoleh hasil perencanaan pelat dengan uraian sebagai berikut: (1) Tebal plat lantai atap $10 \mathrm{~cm}$ dengan tulangan pokok Ø10-200 dan tulangan susut Ø8200. (2) Tebal pelat lantai $12 \mathrm{~cm}$ dengan tulangan pokok $\varnothing 10-200$ dan tulangan susut Ø8-150.

\section{DAFTAR PUSTAKA}

BSN, 2013, Beban Minimum Untuk Perancangan Bangunan Gedung dan Struktur Lain SNI 1727:2013, Jakarta, BSN.

BSN, 2013, Persyaratan Beton Struktural Untuk Bangunan Gedung SNI 2847:2013, Jakarta, BSN.

BSN, 2012, Tata Cara Perencanaan

Ketahanan Gempa Untuk

Struktur Bangunan Gedung dan

Non Gedung SNI 1726:2012, Jakarta, BSN.

Kusuma G., Andriono T., 1993, Desain

Struktur Rangka Beton
Bertulang di Daerah Rawan

Gempa. Jakarta, Erlangga.

Lumantarna B., 2000, Pengantar Analisis Dinamis dan Gempa, Yogyakarta, Andi Offset.

Pawirodikromo W., 2012, Seismologi

Teknik \& Rekayasa Kegempaan,

Yogyakarta, Pustaka Pelajar.

Suharyanto, 2013, Rekayasa Gempa

(Dilengkapi Dengan Analisis

Beban Gempa Sesuai SNI - 03 -

1726 - 2002), Yogyakarta, Kepel Press.

Zebua AW., 2018, Analisis Gaya

Gempa Bangunan Rumah

Tinggal di Wilayah Gempa

Tinggi, SIKLUS: Jurnal Teknik Sipil, Volume 4, Nomor 1, April 2018, 23-35, ISSN: 2549- 3973.

Zebua AW., 2016, Penentuan Besaran

Beban Gempa Bangunan Rumah

Tinggal di Kota Gunungsitoli Kepulauan Nias (statik ekivalen) sesuai dengan SNI 1726:2012, Jurnal DIDAKTIK, Volume 10, Nomor 1, April 2016, 1701-1714, ISSN : 1978-144x. 